Çukurova Üniversitesi Mühendislik Mimarlık Fakültesi Dergisi, 31(ÖS 1), ss. ÖS 117-ÖS 122, Ağustos 2016

\title{
Toz Metal Parçalar ile Çelik Parçaların İndüksiyon ile Sinterleme Yöntemiyle Birleştirilmesi
}

\author{
Enver ATIKK ${ }^{1}$, Can ÇiVï ${ }^{* 1}$, Cansu KÖKEY ${ }^{1}$, Gökhan EYİCi ${ }^{1}$ \\ ${ }^{1}$ Manisa Celal Bayar Üniversitesi, Mühendislik Fakültesi, Makine Mühendisliği Bölümü, \\ Manisa
}

Geliş tarihi: 11.01.2016 Kabul tarihi: 30.03 .2016

\section{Özet}

Bu çalışmada, ST 37-2 çeliği üzerine bakır ve grafit içerikli demir tozu farklı basınçlarda preslenmiş, elde edilen parça indüksiyon ile ve karşılaştırma amaçlı olarak geleneksel sinterleme yöntemleri ile sinterlenerek, çelik ile toz metalden oluşan kademeli malzemeler üretilmiştir. Üretilen numunelere üç nokta eğme testi gerçekleştirilmiştir. Ayrıca numunelerin Rockwell - B sertlik değerleri ve mikro yapıları incelenmiştir.

Anahtar Kelimeler: Toz metalürjisi, Fonksiyonel derecelendirilmiş malzeme, İndüksiyon ile sinterleme, İndüksiyon ile birleştirme

\section{Joining of Powder Metal Parts with Steel Parts by Induction Sintering Method}

\begin{abstract}
In this study, Fe based cupper and graphite included metal powder were pressed on ST 37-2 steel with different pressures. Obtained components were sintered with induction and conventional sintering methods and gradual parts were produced. Three point bending test were applied to produced samples. Also Rockwell-B hardness and microstructures of samples were investigated
\end{abstract}

Keywords: Powder metallurgy, Functionally graded materials, Induction sintering, Joined with induction

\footnotetext{
*Sorumlu yazar (Corresponding author) : Can Çİİ, Manisa Celal Bayar Üniversitesi, Mühendislik Fakültesi, Makine Mühendisliği Bölümü, Manisa, can.civi@cbu.edu.tr
} 


\section{GíRiş}

Toz Metalurjisi, metal tozlarının işlemden geçirilerek yararlı mühendislik parçalarına dönüştürülmesi ile ilgilenir. Toz metalürjisinin ana adımları toz teknolojisi, toz işleme ve üretilen malzemelerin özelliklerinin belirlenmesidir [1]. Tozlar farklı gerilmeler altında sıvılar gibi davranırlar ve şekillendirilebilirler. $\mathrm{Bu}$ özelliklerinden dolayı karmaşık şekilli parçalar kolaylıkla üretilebilir. Şekillendirilen tozlar, istenen mukavemete sinterleme yapılmaksızın sahip olamazlar. Sinterleme geleneksel olarak sinterleme firınlarında gerçekleştirilir [2]. Bunun yanı sıra hızlı sinterleme yöntemleri geleneksel sinterlemeye önemli bir alternatiftir. İndüksiyonla sinterleme, mikrodalga ile sinterleme, plazma sinterleme, lazer sinterleme, deşarj sinterleme, hızlı sinterleme yöntemleridir [3]. İndüksiyon ile sinterleme yöntemi, akımı vasıtası ile oluşan 1sı enerjisinin kullanılarak sinterlemenin gerçekleştirildiği ve hızlı sinterleme yöntemleri adı verilen yöntemlerden bir tanesidir. Hizlı sinterleme yöntemleri, yaygın olarak sinterleme uygulamalarında kullanılmaktadır. Yöntemlerin en önemli avantajı hılı 1sitma/soğuma oranlarına sahip olmaları ve malzemelerin yüksek sıcaklıklara uzun süre maruz kalmasını engelleyerek ince taneli ve yüksek yoğunluklu yapıların elde edilebilmesidir. Ayrıca 1sının geleneksel 1sitmada yüzeyden içeriye doğru yayılması dolayısı ile oluşan sıcaklık gradyanları hızlı sinterleme yöntemleri vasıtası ile önlenir [4-7]. Son yıllarda 1S1 değiştiricilerin üretilmesi gibi uygulamalarda metal plaka üzerine toz katman oluşturma uygulamaları yapılmaktadır. Bu çalışmalarda metal tozu, metal plakaların üzerine preslenip sinterlenerek toz katman oluşturulması hedeflenmiştir [8].

Bu çalışmada, ST 37-2 (ASTM SAE 1015 ) çeliği üzerine demir esaslı toz $600 \mathrm{MPa}$ ve $800 \mathrm{MPa}$ basınçta sinterlenmiş, elde edilen parça indüksiyon ile ve karşılaştırma amaçlı olarak geleneksel sinterleme yöntemleri ile sinterlenerek katmanlı bir malzeme üretilmesi amaçlanmıştır. Ayrıca farklı basınçların ve iki farklı sinterleme yönteminin malzemelerin birleşmeleri üzerindeki etkileri irdelenmiştir.

\section{MATERYAL VE METOT}

\subsection{Materyal}

Deneysel çalışmalarda, alt kısımda malzeme olarak 5 mm kalınlığındaki ST 37-2 (ASTM SAE 1015) çelik sac kullanılmıştır. Çelik sacın üstüne $\% 3 \mathrm{Cu}$, \% 0,5 grafit ve yağlayıcı olarak kenolube içeren ASC 100.29 su atomize demir tozu preslenerek numune üretimi gerçekleştirilmiştir. Deneylerde kullanilan metal tozunun kimyasal ve fiziksel özellikleri ile elek analizi Çizelge 1'de yer almaktadır. St 37 Çeliğinin kimyasal özellikleri ise Çizelge 2'de yer almaktadır.

Çizelge 1. Högenas ASC 100.29 demir tozu kimyasal, fiziksel özellikleri ve elek analizi

\begin{tabular}{|c|c|c|c|c|c|}
\hline \multicolumn{2}{|c|}{$\begin{array}{c}\text { Kimyasal } \\
\text { Özellikler (\%) }\end{array}$} & \multicolumn{2}{c|}{ Fiziksel Özellikler } & \multicolumn{2}{c|}{ Boyut Analizi (\%) } \\
\hline $\mathrm{C}$ & 0,5 & Görünür & \multirow{2}{*}{$2,42 \mathrm{~g} / \mathrm{cm}^{3}$} & $45 \mu \mathrm{m}<$ & 23 \\
\cline { 1 - 3 } \cline { 5 - 6 } & Yoğunluk & & $45-150 \mu \mathrm{m}$ & 69 \\
\hline $\mathrm{O}$ & 0,7 & \multirow{2}{*}{ Akış } & \multirow{2}{*}{$31 \mathrm{~s} / 50 \mathrm{~g}$} & $150-180 \mu \mathrm{m}$ & 8 \\
\cline { 1 - 3 } \cline { 5 - 6 } & & & $>180 \mu \mathrm{m}$ & 0 \\
\hline Demir & Balans & & & & \\
\end{tabular}

Çizelge 2. St 37 çeliğinin kimyasal özellikleri

\begin{tabular}{|l|c|c|c|c|c|c|}
\hline \multicolumn{7}{|c|}{ Kimyasal bileşim (\% ) } \\
\hline Malzeme & $\mathrm{C}$ & $\mathrm{Si}$ & $\mathrm{Mn}$ & $\mathrm{P}$ & $\mathrm{S}$ & Fe \\
\hline SG7 & 0.17 & 0.3 & 0.3 & 0.05 & 0.05 & Kalan \\
\hline
\end{tabular}

\subsection{Metot}

Çelik üzerine tozların presleme işlemi 600 ve 800 MPa basınç altında gerçekleştirilmiştir. Preslenen numunelerin şematik gösterimi Şekil 1'de yer almaktadır.

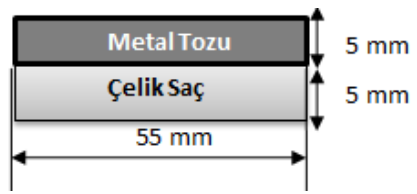

Şekil 1. Numunelerin presleme şekli

Preslenen numuneler, geleneksel olarak ve indüksiyon ile $1120^{\circ} \mathrm{C}$ sicaklıkta sinterlenmiştir. Geleneksel sinterleme işlemi klasik direnç firınında gerçekleştirilmiştir. İndüksiyon ile sinterleme işleminin gerçekleştirildiği sinterleme düzeneği Şekil 2'de görülmektedir. 


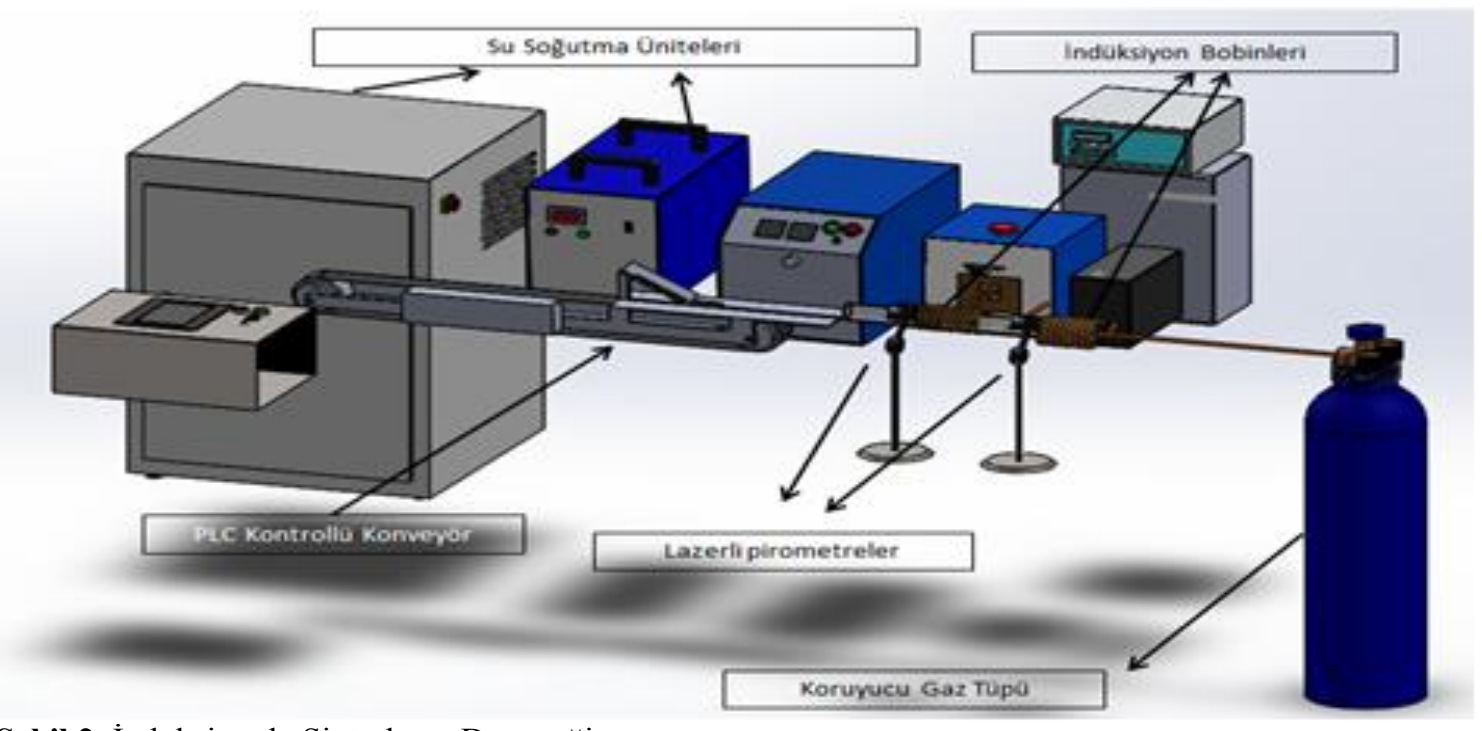

Şekil 2. İndüksiyonla Sinterleme Düzeneği

Sinterleme süresi geleneksel sinterlemede 30 dakika, indüksiyon ile sinterlemede ise 15 dakika olarak belirlenmiş̧tir. Numuneler sinterlemeden sonra 3 nokta eğme deneyine tabi tutulmuşlardır. Üç nokta eğme testi $100 \mathrm{kN}$ kapasiteli SHIMADZU-AG marka cihazda $2 \mathrm{~mm} / \mathrm{dk}$ hizda yapılmıştır. Test, numuneler ayrılıncaya kadar sürdürülmüş ve numunelerin ayrılmaya kadarki taşıdığı gerilmeler elde edilmiștir. Üç nokta eğme deneyinin haricinde, numunelerin Rockwell-B sertlikleri incelenmiştir. Rockwell-B sertlik testleri BMS 200 RB marka cihazda $100 \mathrm{~kg}$ (981 Newton) kuvvet ile ASTM E18-12 standardina uygun olarak gerçekleştirilmiştir. Son olarak Mikro yapı incelemeleri için numuneler Struers labotom-3 marka hassas kesme cihazı ile kesildikten sonra çeşitli gridlerdeki zımparalar ile parlatma cihazında zımparalanıp 3 ve 1 mikron'luk elmas solüsyon ile parlatılırmıştır. Parlatma işleminin ardından numuneler \%3'lük nital çözeltisinde dağlanıp, mikroyapı görüntüleri Nicon Eclipse LV150 marka optik mikroskopta elde edilmiştir. Deney sonuçları ilerleyen kısımda yer almaktadır.

\section{BULGULAR VE TARTIŞMA}

Sinterlemelerden sonra $800 \quad \mathrm{MPa}$ basınçta preslenen ve indüksiyon ile sinterlenen

numunelerin toz metal kısımlarının ile çelik kısımlarının birbiri ile birleştiği, diğer numunelerde ise yüzeylerde çizgi şeklinde ayrıklar olduğu görülmüştür. Numunelerin sinterleme sonrası görüntüleri Şekil 3 'te yer almaktadır.

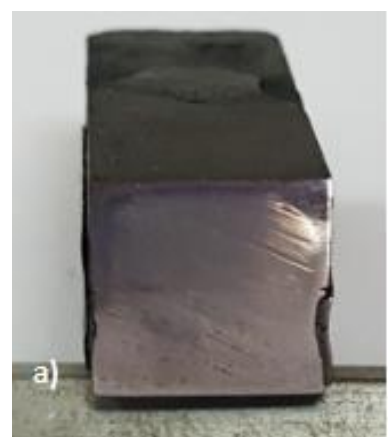

Şekil 3. Numunelerin Görüntüleri a) Sinterleme sonras1 preslenen indüksiyon ile sinterlenen numune) b) Ayrik numune (800 $\mathrm{MPa}$ basınçta preslenen, geleneksel sinterlenen numune

Sinterleme sonrasında Numunelere uygulanan Üç nokta eğme deneyi ve Rockwell-B sertlik incelemesi ile mikro yapı incelemelerinin sonuçları aşağıda yer almaktadır. 


\section{1. Üç Nokta Eğme Deney Sonuçları}

Uygulanan üç nokta eğme deneyi sonuçları Çizelge 3’te verilmiştir.

Çizelge 3. Numunelerin üç nokta eğme deney sonuclar1

\begin{tabular}{|l|c|c|}
\hline \multirow{2}{*}{$\begin{array}{l}\text { Sinterleme } \\
\text { Yöntemi }\end{array}$} & \multicolumn{2}{|c|}{ Üç Nokta Eğme Dayanımı } \\
\cline { 2 - 3 } & $600 \mathrm{MPa}$ & $800 \mathrm{MPa}$ \\
\hline $\begin{array}{l}\text { Geleneksel } \\
\text { Sinterleme }\end{array}$ & $181,77 \mathrm{Nmm}^{2}$ & $190,39 \mathrm{Nmm}^{2}$ \\
\hline $\begin{array}{l}\text { Indüksiyonla } \\
\text { Sinterleme }\end{array}$ & $418,95 \mathrm{~N} \mathrm{~mm}{ }^{2}$ & $287,21 \mathrm{Nmm}^{2}$ \\
\hline
\end{tabular}

Üç nokta eğme dayanımı değerleri incelendiğinde, indüksiyon ile birleştirilen numunelerin dayanım değerlerinin firında birleştirilen numunelere göre daha yüksek olduğu görülmüştür. $\mathrm{Bu}$ da indüksiyon ile isitmada numuneler arası birleşmenin daha iyi olduğunu göstermektedir. Bunun yanı sıra, deney sonuçları incelendiğinde, geleneksel sinterlemede presleme basıncıyla üç nokta eğme dayanımı artarken, indüksiyon ile sinterlemede bu olguya rastlanamamıştır.

\subsection{Rockwell-B Sertlik Ölçümü Sonuçları}

Uygulanan Rockwell-B sertlik ölçümü sonuçları Çizelge 4'te verilmiştir.
Cizelge 4. Rockwell-B sertlik ölçümü sonuçları

\begin{tabular}{|l|c|c|c|c|}
\hline \multirow{2}{*}{$\begin{array}{l}\text { Sinterleme } \\
\text { Yöntemi }\end{array}$} & \multicolumn{4}{|c|}{ Basınç } \\
\cline { 2 - 5 } & $\begin{array}{c}\text { Çelik } \\
\text { Bölge }\end{array}$ & $\begin{array}{c}\text { TM } \\
\text { Bölge }\end{array}$ & $\begin{array}{c}\text { Çelik } \\
\text { Bölge }\end{array}$ & TM Bölge \\
\hline $\begin{array}{l}\text { Geleneksel } \\
\text { Sinterleme }\end{array}$ & $28 \mathrm{HRB}$ & $35,5 \mathrm{HRB}$ & $32 \mathrm{HRB}$ & $39,5 \mathrm{HRB}$ \\
\hline $\begin{array}{l}\text { Indüksiyonla } \\
\text { Sinterleme }\end{array}$ & $44 \mathrm{HRB}$ & $\begin{array}{c}54,5 \\
\mathrm{HKB}\end{array}$ & $41 \mathrm{HRB}$ & $52,6 \mathrm{HRB}$ \\
\hline
\end{tabular}

Rockwell B sertlik sonuçlarına göre, toz metal kısmın sertlik değerleri, hem indüksiyon ile hem de geleneksel 1sitma ile birleştirilen numunelerde çelik kısma göre daha yüksektir. Metal tozunda bulunan \%0,5 grafit ve $\% 3 \mathrm{Cu}$ vasitası ile, toz kısım düşük karbonlu çelik yapıdan daha yüksek sertlik değerlerine sahiptir. Ayrıca toz metal parçaların indüksiyon ile sinterleme prosesinde, hızlı 1sınmadan ve indüksiyon akımının numunelere yaptığ fiziksel ve kimyasal etkilerden dolay1, geleneksel sinterlemeye oranla daha iyi mekanik özellikler elde edilebilmektedir [8]. Bu çalışmada toz metal malzeme ile çelik malzemenin birleştirilmesinde kullanılan indüksiyon akımı ile de daha iyi birleşme dayanımı elde edilmiştir.

\subsection{Metalografik İncelemeler}

Numunelerin mikro yapı fotoğrafları Şekil 4-7'de yer almaktadır.
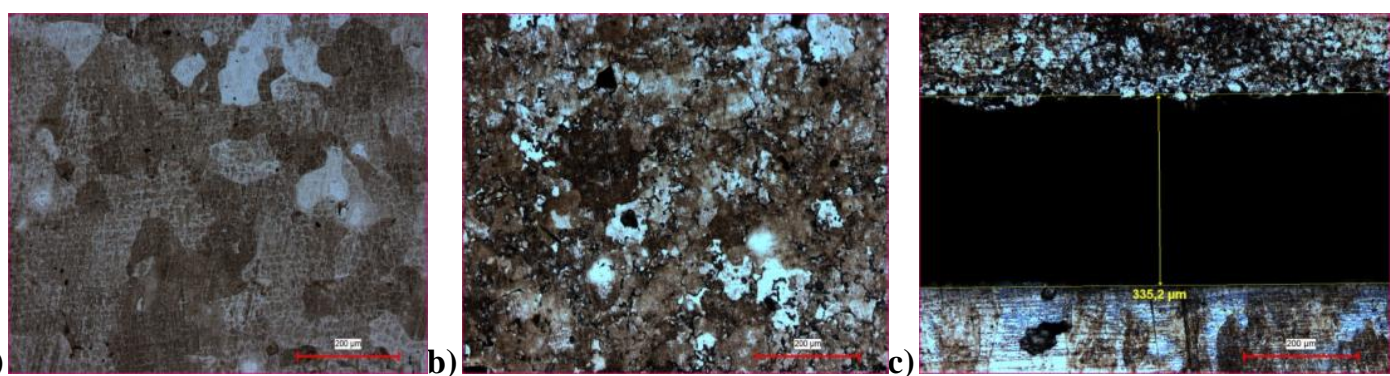

Şekil 4. $600 \mathrm{MPa}$ basınçta preslenen geleneksel olarak sinterlenen numunelerin mikro yapı görüntüsü a) Çelik kısım b) Toz metal kısım c) Geçiş bölgesi 
a)
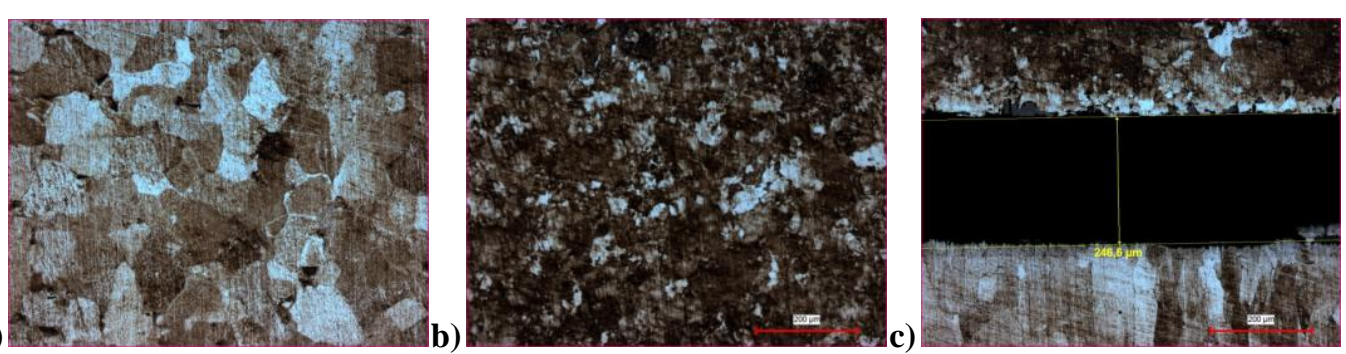

Şekil 5. $800 \mathrm{MPa}$ basınçta preslenen geleneksel olarak sinterlenen numunelerin mikro yapı görüntüsü a) Çelik kısım b) Toz metal kısım c) Geçiş bölgesi

a)

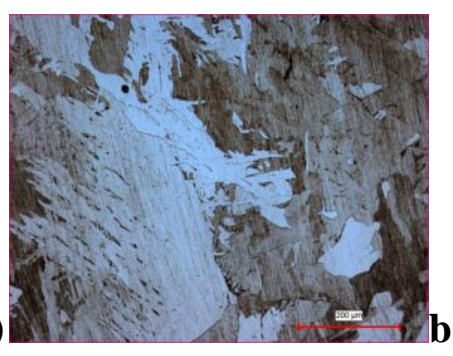

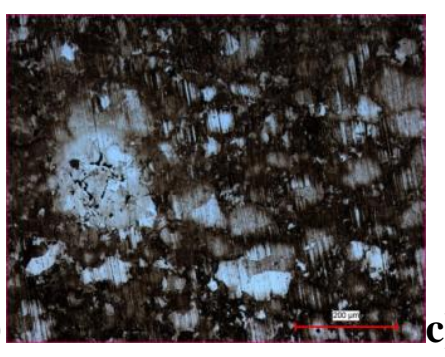

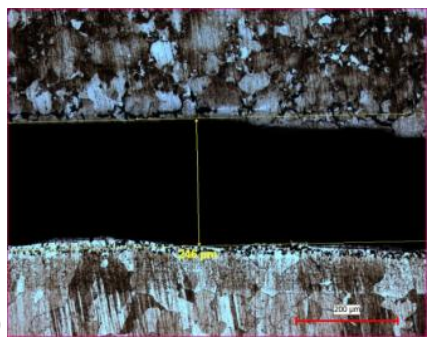

Şekil 6. $600 \mathrm{MPa}$ basınçta preslenen indüksiyon ile sinterlenen numunelerin mikro yapı görüntüsü a) Çelik kısım b) Toz metal kısım c) Geçiş bölgesi
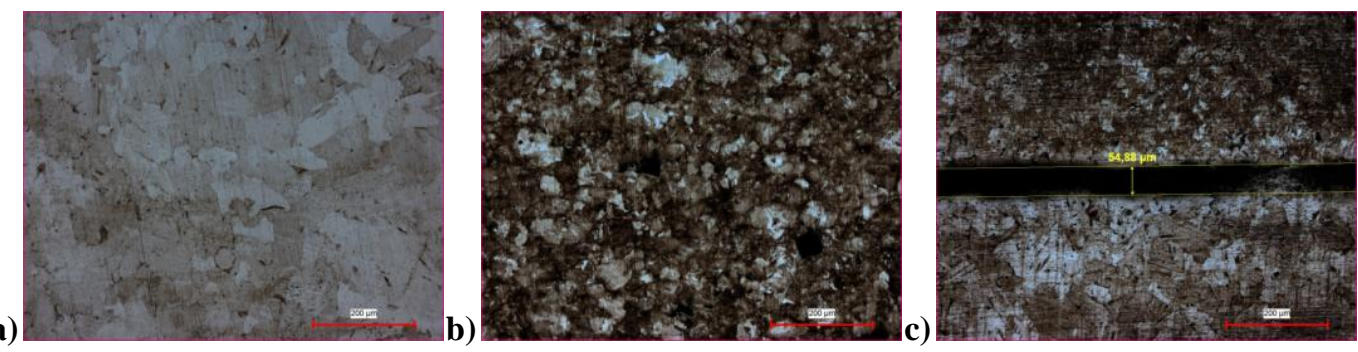

Şekil 7. $800 \mathrm{MPa}$ basınçta preslenen indüksiyon ile sinterlenen numunelerin mikro yapı görüntüsü a) Çelik kısım b) Toz metal kısım c) Geçiş bölgesi

Numune birleștirmelerinde numunelere herhangi bir yüzey işlemi uygulanmamıştır. Ayrıca tutunmayı artırma amaçlı bir ara yüzey de uygulanmamıştır. $\mathrm{Bu}$ nedenle numunelerin mikro yap1 fotoğraflarında ayrık kalan kısımlar görülmüştür. $800 \mathrm{MPa}$ basınçta birleştirilen numunelerde, ayrılma yüzeyi $600 \mathrm{MPa}$ da birleştirilenlere göre daha kısa iken (geleneksel sinterlemede $335,2-246,6 \mu$, indüksiyon ile sinterlemede 246-54,88 $\mu$ ) indüksiyon ile sinterlenen numunelerde ayrilma yüzeyi geleneksel sinterlemeye göre daha kısadır. Bu da indüksiyon ile sinterlemede difüzyonun geleneksel sinterlemeye göre daha iyi olduğunu göstermektedir. $800 \mathrm{MPa}$ basınçta sinterlenen numunelerde, gözle görülür bir ayrılma yüzeyi yoktur. Mikroyapıda da kısım kısım ayrılan yüzeyler gözlenmiştir, bazı bölgelerin tam olarak birleştiği gözlemlenmiştir.

\section{SONUÇLAR}

$\mathrm{Bu}$ çalışmada çelik üzerine kademeli olarak preslenen toz metal parçaların sinterleme işlemleri indüksiyon ile ve geleneksel sinterleme metotları ile farklı basınç parametrelerinde gerçekleştirilmiştir. Sonuçlar incelendiğinde; 
- $800 \mathrm{MPa}$ basınç altında sinterlenen parçaların $600 \mathrm{MPa}$ basınçta sinterlenenlere göre daha iyi birleşim gösterdiği görülmüştür.

- İndüksiyon ile sinterlenen numunelerin, geleneksel sinterlenenlere göre iyi birleştiği görülmektedir. İndüksiyon ile $800 \mathrm{MPa}$ basınç altında sinterlenen numunelerde tam birleşmeye yakın bir sonuç elde edildiği görülmüştür. $\mathrm{Bu}$ da indüksiyon akımı altında difüzyonun daha yüksek olduğunu göstermiştir.

- İlerleyen çalışmalarda birleşme yüzeylerinde oluşan açıklığın giderilmesi için çelik plakanın yüzey pürüzlülüğü artırılarak daha iyi tutunma özelliği sağlanabilir.

- Yapışma özelliği sağlayabilecek bir ara malzemeyle ya da kısmi bir sıvi faz oluşumu ile de daha iyi bir birleşme sağlanabileceği ön görülmektedir.

\section{KAYNAKLAR}

1. German, R. M. Editörler; Durlu, N., Sarıtaş, S. Türker, M., 2007. Toz ve Parçacıklı Malzeme İşlemleri, TMMD, Ankara.

2. German, R. M. Çeviri: Gülsoy, H. O., 2014. Sinterleme Teorisi ve Uygulamaları, Nobel Yayınevi, Ankara.

3. Atik, E., Çavdar, U., 2011. Geleneksel ve Hızlı Sinterleme Yöntemleri, CBÜ Soma Meslek Yüksekokulu Teknik Bilimler Dergisi Cilt 1, Say1:15.

4. Li, W. Gao, L. 2000. Rapid sintering of nanocrystalline $\mathrm{ZrO}_{2}(3 \mathrm{Y})$ by spark plasma sintering. Journal of the European Ceramic Society. 20, p. 2441-2445.

5. Hamer, M. P., Brook, R. J., 1981. Fast firingmicrostructural benefits. Journal of the British Ceramic Society. 80, p.147-149.

6. Hamer, M. P., Roberts, E. V., Brook, R. J., 1979. Rapid sintering of pure and doped a$\mathrm{Al}_{2} \mathrm{O}_{3}$. Transactions of the British Ceramic Society. 78, p. 22-25.

7. Morell, A., Mermosin, A., 1980. Fast sintering of soft $\mathrm{Mn}-\mathrm{Zn}$ and $\mathrm{Ni}-\mathrm{Zn}$ ferrite pot cores.
Bulletin : American Ceramic Society 59, p. 626-629.

8. Çivi, C., 2016. Toz Metal Parçaların Orta ve Düşük Frekansli Indüksiyon ile Sinterlenmesinde Sinterleme Parametrelerinin Mekanik Özelliklere Etkisinin İncelenmesi, Doktora Tezi, Celal Bayar Üniversitesi Makine Mühendisliği Bölümü Konstrüksiyon ve İmalat Anabilim Dalı. 